\title{
FORMAÇÃO CONTINUADA ONLINE para docentes QUE ATUAM NO ATENDIMENTO PEDAGÓGICO AO ESCOLAR EM TRATAMENTO de SAÚDE
}

\author{
Jacques de Lima Ferreira*
}

Marilda Aparecida Behrens**

\begin{abstract}
RESUMO
Este artigo tem o objetivo de analisar um processo de formação continuada online que foi ofertado aos professores que atuam no atendimento pedagógico ao escolar em tratamento de saúde (APETS), durante uma pesquisa aprovada pelo CNPq "Eureka - Ambiente Virtual favorecendo a formação continuada online dos professores que atuam com escolares em tratamento de saúde". A problemática investigada foi a seguinte: Como a formação continuada na modalidade online pode contribuir para o desenvolvimento profissional dos professores que atuam no atendimento pedagógico ao escolar em tratamento de saúde e quais as repercussões dessa formação pedagógica? Numa abordagem qualitativa do tipo estudo de caso que envolveu 295 docentes de diversos estados brasileiros que atuam no APETS. Os dados foram coletados a partir de dois questionários (processual e diagnóstico), com perguntas abertas e fechadas que propiciaram a análise de conteúdo baseada na perspectiva de Bardin (2011), e contou com o auxílio do software Atlas Ti. Os resultados revelaram que o processo de formação online ofertado aos professores que atuam no APETS contribui para o desenvolvimento profissional docente quando os construtos trabalhados na formação continuada contemplam a relação entre educação e saúde, numa visão inovadora que garanta a conexão entre a teoria e a prática.
\end{abstract}

Palavras-chave: Educação. Saúde. Educação online. Formação continuada. Desenvolvimento profissional.

\section{ABSTRACT \\ ONLINE CONTINUING EDUCATION FOR TEACHERS WHO WORK IN THE EDUCATIONAL SERVICE TO STUDENTS IN HEALTH CARE \\ This article aims to analyze an online continuing education process which was offered to teachers who work in the educational service to the students in health treatment (APETS) during a research approved by CNPq "Eureka - Virtual Environment favoring}

\footnotetext{
* Doutor em Educação pela Pontifícia Universidade Católica do Paraná (PUCPR). Professor do Mestrado Profissional em Educação e Novas Tecnologias do Centro Universitário Internacional (UNINTER). Integrante do Grupo de Pesquisa Paradigmas Educacionais e Formação de Professores da Pontifícia Universidade Católica do Paraná (PUCPR). E-mail: drjacqueslima@, hotmail.com

** Doutora em Educação pela Pontifícia Universidade Católica de São Paulo (PUCSP). Professora Titular do Programa de Pós-Graduação em Educação da Pontifícia Universidade Católica do Paraná (PUCPR). Integrante do Grupo de Pesquisa Paradigmas Educacionais e Formação de Professores da Pontifícia Universidade Católica do Paraná (PUCPR). E-mail: marildaab@ gmail.com
} 
the online continuing education of teachers who work with students in health care". The issue investigated was: How can the online continuing education contribute to the professional development of teachers who work in the educational service to the students on health care and what the implications of such educational training are? In a case study qualitative approach which involved 295 teachers from several states who work at APETS. Data were collected from two questionnaires (procedural and diagnosis), with open and closed questions which made possible the content analysis based on the perspective of Bardin (2011), using the help of Atlas Ti software. The results showed that the online continuing education process offered to teachers who work at APETS contributes to the professional development of teachers when the constructs given in continuing education include the relation between education and health, in an innovative vision that ensures the connection between theory and practice.

Keywords: Education. Health. Online education. Continuing Education. Professional development.

\section{RESUMEN}

\section{FORMACIÓN CONTINUA ONLINE PARA MAESTROS QUE ACTUAN EN EL ATENDIMIENTO PEDAGÓGICO DEL ESTUDIANTE EN TRATAMIENTO DE} SALUD

Este artículo tiene como objetivo analizar un proceso de educación continua en red (online) que se ofreció a los maestros que trabajan en el servicio educativo del estudiante en tratamiento de salud (APETS) durante un estudio aprobado por el CNPq "Eureka - Ambiente virtual que favorece la educación continua online de maestros que trabajan con estudiantes en tratamiento de la salud". La problemática investigada fue la siguiente: ¿Cómo la formación continua en la modalidad online puede contribuir para el desarrollo profesional de los docentes que trabajan en el servicio educativo del estudiante en tratamiento de la salud y cuáles son las implicaciones de este tipo de formación educativa? En un enfoque cualitativo tipo estudio de caso que involucró 295 maestros de varios estados que trabajan en APETS. Los datos fueron recogidos a partir de dos cuestionarios (de procedimiento y diagnóstico), con preguntas abiertas y cerradas que proporcionaron el análisis de contenido basado en la perspectiva de Bardin (2011), y contó con la ayuda del software Atlas Ti. Los resultados mostraron que el proceso de formación en la red que se ofrece a los maestros que trabajan en APETS contribuye al desarrollo profesional de los maestros cuando las construcciones trabajadas en la educación continua incluyen la relación entre la educación y la salud, una visión innovadora que asegura la conexión entre la teoría y la práctica.

Palabras clave: Educación. Salud. La educación en la red. La formación continua. Desarrollo profesional.

\section{Introdução}

A atuação do docente na contemporaneidade precisa atender a complexa realidade da educação nos seus diferentes níveis e contextos de ensino, ${ }^{1}$

1 Entendemos diferentes níveis e contextos como: os diferentes níveis de atuação profissional que o docente pode ter durante sua profissio- principalmente daquela que acontece além dos muros da escola, que, em geral, não são trabalhanalização, ou seja, na educação básica e na educação superior, e os diferentes contextos, a docência em diversos ambientes, ou seja, na escola regular ou na atuação em diferentes espaços de escolaridade, tanto na modalidade presencial quanto online. 
das nos cursos de Pedagogia, mas que requerem formação de professores com uma visão mais ampla, que acolham uma nova abordagem em relação ao processo de ensino e de aprendizagem, ou seja, um redirecionamento paradigmático na prática pedagógica conservadora para que se torne significativa na vida do aluno. Nesse contexto, entendemos como educação que acontece além dos muros da escola a educação não formal, que se apresenta hoje como:

Um processo sociopolítico, cultural e pedagógico de formação para a cidadania, entendendo o político como a formação do indivíduo para interagir com o outro em sociedade. Ela designa um conjunto de práticas socioculturais de aprendizagem e de produção de saberes, que envolve organizações/instituições, atividades, meios e formas variadas, assim como uma multiplicidade de programas e projetos sociais. (GOHN, 2010, p. 33).

$\mathrm{Na}$ atualidade, temos diferentes contextos de ensino em que a educação não formal é direcionada a escolares que estão passando por algum problema de saúde e que precisam dar continuidade ao seu processo de escolarização e de formação fora do ambiente físico da escola. As crianças e os adolescentes que se encontram em tratamento de saúde podem continuar sua escolarização dentro do hospital, nas casas de apoio, nos centros de reabilitação, nas ONGs e até por atendimento domiciliar, e podem obterem aprovação legal das escolas em que estão matriculadas. Assim, como realidade dentro do curso de Pedagogia, podemos oferecer uma formação que subsidie a atuação destes profissionais também na modalidade de educação não formal, ou seja, em outros contextos.

Entre os outros contextos de atuação do pedagogo, destaca-se a atuação docente no ambiente hospitalar com alunos em tratamento de saúde, permitindo a continuidade do processo de escolarização. Diante dos diferentes ambientes em que podem ocorrer a aprendizagem e a escolarização, os alunos estão sendo atendidos na continuidade dos seus estudos e ao mesmo tempo se recuperando de um problema de saúde. Nesta pesquisa, após discussões sobre esta temática, optamos por denominar esta modalidade de Atendimento Pedagógico ao Escolar em Tratamento de Saúde (APETS), sendo a modalidade de educação não formal que acontece nos diferentes níveis e contextos de ensino ao aluno em tratamento de saúde.

Nessas realidades de ensino em que acontece o APETS, a docência exige do professor uma nova postura, assentada numa mudança de abordagem, que neste momento aponta para o paradigma da complexidade (MORIN, 2000), que propicia uma visão de todo, que demanda uma prática pedagógica que possibilite a aprendizagem em diferentes níveis e contextos de ensino e que atenda a diversidade que está presente na sociedade. Diante desses fatos, dessa nova visão social, é reconhecida a importância de se repensar e transformar a formação do professor que atua no APETS. Sabemos que a formação de um professor é algo complexo que perpassa por grandes desafios, mas também reconhecemos que a formação docente que se apresenta na atualidade necessita de redimensionamento e de nova organização do trabalho para atender a um novo paradigma que respeite as necessidades dos alunos na sociedade contemporânea.

É diante do aperfeiçoamento profissional que o professor pode aprimorar a sua prática pedagógica e, consequentemente, melhorar o processo de ensino e aprendizagem, a qualidade da educação. Essa problemática tem ocupado espaço na atuação dos professores, pois percebemos inúmeras dificuldades e dilemas que a docência enfrenta na contemporaneidade, principalmente em relação à educação que acontece fora da instituição formal de ensino. Obstáculos esses que podem ser ultrapassados e vencidos, em geral, decorrem da falta de uma formação pedagógica específica para o atendimento pedagógico, e neste caso, a falta de conhecimento e de preparo para atuar com o escolar em tratamento de saúde.

$\mathrm{O}$ acolhimento e entendimento de novos papéis e a superação da falta de preparo pedagógico necessitam de oferta de processo de formação continuada que possa subsidiar o desenvolvimento profissional ao longo da vida docente. A formação contínua permite estudos e aprofundamentos, discussão entre pares, reflexões, pesquisas e o permanente contato com novas concepções e abordagens de ensino, neste caso, atendendo ao paradigma da complexidade (MORIN, 2000), para que os professores estabeleçam os processos de mudanças e melhorias na sua prática pedagógica. 
Nessa perspectiva da formação, um maior esclarecimento deve ser realizado perante a indagação: "como" acontece o processo de formação continuada na modalidade de educação online dos professores que atuam no APETS e as repercussões dessa formação pedagógica no desenvolvimento profissional docente? Quais são as implicações e contribuições dessa formação pedagógica na profissionalidade docente? Esses questionamentos geraram a problematização que é o foco central da pesquisa deste artigo, com o seguinte problema de pesquisa: Como a formação continuada online pode contribuir para o desenvolvimento profissional dos professores que atuam no atendimento pedagógico ao escolar em tratamento de saúde e quais as repercussões dessa formação pedagógica? Este artigo visa responder esta questão, tomando como estudo de caso a formação continuada online, especificamente um curso de extensão que foi ofertado aos docentes que atuam no APETS.

$\mathrm{Na}$ busca de respostas para o problema que norteia este artigo, temos como objetivo: analisar o processo de formação continuada online ofertada aos professores que atuam no APETS e as repercussões dessa formação para o desenvolvimento profissional docente, a fim de indicar pontos norteadores para uma futura formação pedagógica aos docentes que atuam com escolar em tratamento de saúde. As discussões do artigo estão focadas nas relações entre educação e saúde, com ênfase no processo de formação continuada do professor que atua na educação não formal.

\section{Construtos sobre Educação e Saúde como eixo articulador na atuação dos Professores no APETS}

A busca de construtos teóricos e práticos para fundamentar a formação de professores que atuam nos APETS levou a eleger a conexão entre educação e saúde. Iniciamos esta investigação com a discussão sobre o conceito de educação e saúde, com o objetivo conectar estas duas áreas do conhecimento que se agregam, se inter-relacionam e se cruzam no APETS. Discutimos sobre a mudança paradigmática necessária na educação e na saúde para o atendimento pedagógico ao escolar em tratamento de saúde.
Os paradigmas podem ser entendidos como a gama de crenças, valores e técnicas partilhadas pelos membros de uma comunidade científica. Portanto, os paradigmas caracterizam um determinado tempo histórico e contagiam todas as instituições que compõem a sociedade. Os paradigmas permitem entender os aportes teóricos, a explicação da prática dos profissionais e os costumes da população. Os paradigmas determinam o ser e o fazer das pessoas na sociedade.

A conexão educação e saúde, numa visão complexa, foi contemplada ao longo da elaboração e da proposição da pesquisa e considerada a todo tempo na elaboração do curso ofertado aos professores que atuam no APETS de diferentes estados do Brasil. As discussões e aprofundamentos de estudo do tema permitiram elaborar alguns construtos sobre educação e saúde necessários para a formação numa visão inovadora.

A educação é um termo polissêmico, e segundo Mialaret (2013) pode receber pelo menos quatro significados. O primeiro, como instituição social, um sistema educacional. "A educação como instituição possui suas estruturas, suas regras de funcionamento, mesmo que essas sejam pouco precisas ou pouco explicitadas [...]". O segundo, a educação como resultado de uma ação. "Recebemos uma boa ou má educação; somos produto de uma educação clássica por oposição ao que recebeu uma educação técnica. Na verdade, nós nos situamos assim no plano do indivíduo, que é de certo modo o resultado, o produto, diriam os economistas [...]" (MIALARET, 2013, p. 68-69). O terceiro significado do termo "educação" refere-se ao próprio processo, que liga de uma forma prevista ou imprevista dois ou vários seres humanos e que os põe em comunicação, em situação de trocas e de modificações recíprocas (MIALARET, 2013, p. 70). O último e quarto significado da educação está "relacionado com o "conteúdo", quer dizer, com os programas (o curriculum dos anglo-saxões). "De fato, uma educação se caracteriza também pelo tipo de atividades que ela propõe (e com base na qual se desenvolve), pelo conjunto dos conhecimentos, informações que ela apresenta aos alunos" (MIALARET, 2013, p. 70).

A educação pode ser compreendida como a apropriação da herança cultural produzida pelas 
gerações do passado e do presente, pela qual os homens utilizam dela para se desenvolver e evoluir socialmente. $\mathrm{O}$ processo educativo apresenta-se multifacetado, concebido a partir das interações dos sujeitos com seus saberes em um determinado contexto histórico e social.

A Constituição Federal (1988) define a educação como: "Art. 205. A educação, direito de todos e dever do Estado e da família, será promovida e incentivada com a colaboração da sociedade, visando ao pleno desenvolvimento da pessoa, seu preparo para o exercício da cidadania e sua qualificação para o trabalho" (BRASIL, 1988). Entretanto, a mesma Constituição Federal (1988) esclarece que no Art. 196. "A saúde é direito de todos e dever do Estado, garantido mediante políticas sociais e econômicas que visem à redução do risco de doença e de outros agravos e ao acesso universal e igualitário às ações e serviços para sua promoção, proteção e recuperação" (BRASIL, 1988). A Organização Mundial de Saúde (OMS) define saúde não apenas como a ausência de doença, mas como uma situação de perfeita sintonia entre bem-estar físico, mental e social.

Assim como a educação, o termo saúde apresenta-se polissêmico. O termo saúde apresenta fatores que compõe a sua definição como: trabalho, alimentação, saneamento, moradia, educação, lazer, entre outros, sendo indispensáveis para a saúde, sendo a saúde um estado de bem-estar físico, mental e social. Portanto, o entendimento de saúde está atrelado à qualidade de vida.

Os conceitos de educação e saúde são processos complexos, amplos, que se interligam, são campos que coexistem, um na dependência do outro. Educação e saúde constituem-se um campo epistêmico complexo que prioriza a condição humana, a multidimensionalidade e a complexidade do homem no mundo e suas relações.

Educação e Saúde são direitos que devem estabelecer uma relação que possibilite o desenvolvimento biopsicossocial do homem, possibilitando qualidade de vida e condição para o desenvolvimento humano.

A educação do século XXI apresenta-se complexa e dinâmica, na qual professores e alunos estão em diferentes níveis e contextos de ensino e aprendizagem. Libâneo (2010, p. 30) enfatiza que a educação é: “[...] o conjunto das ações, processos, influências, estruturas, que intervêm no desenvolvimento humano de indivíduos e grupos na sua relação ativa com o meio natural e social, num determinado contexto de relações entre grupos e classes sociais". Já a docência, na atualidade, apresenta características diferenciadas, o professor não tem a sua profissionalidade somente na escola, a sua prática pedagógica acontece em diferentes ambientes.

Como a educação está em toda parte, sempre aprendemos ou ensinamos algo a alguém diante da educação formal, não formal e informal. Libâneo (2010, p. 31) distingue a educação como: informal, não formal e formal:

A educação informal corresponderia a ações e influências exercidas pelo meio, pelo ambiente sociocultural, e que se desenvolve por meio das relações dos indivíduos e grupos com seu ambiente humano, social, ecológico, físico e cultural, das quais resultam conhecimentos, experiências, práticas, mas que não estão ligadas especificamente a uma instituição, nem são intencionais e organizadas. A educação nãoformal seria a realizada em instituições educativas fora dos marcos institucionais, mas com certo grau de sistematização e estruturação. A educação formal compreenderia instâncias de formação, escolares ou não, onde há objetivos educativos explícitos e uma ação intencional institucionalizada, estruturada, sistemática.

O processo educativo acontece em diferentes contextos que possibilitam a democratização da educação e a inclusão de todos. Brandão ressalta também que "[...] não há uma forma única nem um único modelo de educação; a escola não é o único lugar em que ela acontece e talvez nem seja o melhor; o ensino escolar não é a única prática [...]" (BRANDÃO, 2007, p. 9). Os diferentes contextos de ensino são espaços de escolarização da educação formal e não formal em que o processo de ensino e aprendizagem pode ocorrer na perspectiva presencial ou a distância.

Os diferentes contextos de atuação docente, diante da concepção do APETS, são todos aqueles ambientes nos quais ocorre o processo de ensino e aprendizagem ao escolar que está em tratamento de saúde, que podem ser: hospitais, clínicas, ONGs, casas de apoio, na residência do aluno, brinquedo- 
teca, entre outros. Na educação formal e não formal a presença de um professor se faz necessária, um profissional que construiu sua formação com habilidades e competências diante de vários saberes, teóricos e práticos que acompanham as mudanças sociais, políticas e econômicas que interferem diretamente na educação, e, consequentemente, também influencia a formação docente. Diante dessa perspectiva, Ferreira (2013, p. 166) enfatiza que:

Atualmente muitas pesquisas, discursos e manifestos relatam e anunciam a necessidade de uma prática pedagógica que atenda às premências da realidade complexa que a educação na contemporaneidade apresenta. Uma dessas necessidades que a realidade social exige é a presença do professor na educação não formal, aquela que acontece fora dos muros da escola, no hospital, em casa, em ONGs, centros de reabilitações entre outros ambientes.

A ação pedagógica com os escolares em tratamento de saúde necessita acolher o paradigma da complexidade, assim, tem o objetivo de escolarizar e contribuir nos processos educativos a partir de uma visão democrática e inclusiva de educação para todos, bem como proporcionar ao aluno o contato com o saber, compreendendo que o processo de ensino-aprendizagem amplia as possibilidades de diálogo com o mundo.

\section{Legislações que garantem aos alunos o Atendimento Pedagógico ao Escolar em Tratamento de Saúde (APETS)}

O termo APETS denomina o atendimento pedagógico ao escolar em tratamento de saúde. Trata-se de uma modalidade de educação não formal, que legalmente apresenta-se como um direito presente na Constituição Federativa Brasileira de 1988, que assim expressa: "A educação, direito de todos e dever do Estado e da família, será promovida e incentivada com a colaboração da sociedade, visando ao pleno desenvolvimento da pessoa, seu preparo para o exercício da cidadania e sua qualificação para o trabalho" (BRASIL, 1988).

Outra garantia legal está presente no Estatuto da Criança e do Adolescente, Lei n ${ }^{\circ} 8.069$, de 13 de junho de 1990, que dispõe de garantias ao direito para crianças e adolescentes à saúde e à continuidade de sua escolarização. A Lei enfatiza que: "Art. $7^{\circ}$ - A criança e o adolescente têm o direito à proteção $\mathrm{e}$ à vida e à saúde, mediante efetivação de políticas sociais públicas que permitem o nascimento e o desenvolvimento sadio e harmonioso, em condições dignas de existência” (BRASIL, 1990).

Outra recomendação da Lei evidencia que: “Art. 57 - O Poder Público estimulará pesquisas, experiências e novas propostas relativas a calendário, seriação, currículo, metodologia, didática e avaliação, com vistas à inserção de crianças e adolescentes excluídos do ensino fundamental obrigatório" (BRASIL, 1990). Também para consolidar esse direito, a Câmara de Educação Básica do Conselho Nacional de Educação instituiu as Diretrizes Nacionais para a Educação Especial na Educação Básica, Resolução CNE/CEB n 2, de 11 de setembro de 2001, que no artigo 13 enfatizando que:

Art. 13. Os sistemas de ensino, mediante ação integrada com os sistemas de saúde, devem organizar $\mathrm{o}$ atendimento educacional especializado a alunos impossibilitados de frequentar as aulas em razão de tratamento de saúde que implique internação hospitalar, atendimento ambulatorial ou permanência prolongada em domicílio. (BRASIL, 2001).

\section{É importante destacar que no Brasil o APETS} é pouco conhecido, principalmente pelos profissionais da educação, e grande parte da sociedade desconhece esse processo de escolarização não formal, ou seja, o direito à educação e saúde. Alguns municípios e estados brasileiros possuem suas próprias legislações municipais e/ou estaduais para esse atendimento, principalmente quando ele acontece no ambiente hospitalar. Os demais contextos nos quais acontece a escolarização do aluno em tratamento de saúde vêm crescendo a cada ano por causa das demandas sociais. Cabe ressaltar que mesmo amparados legalmente, muitos estados da União não oferecem este direito à criança e ao adolescente convalescente.

Os diferentes contextos de atuação como hospitais, ONGs, casas de apoio, clínicas e a própria residência do aluno são ambientes em que o professor atua na contemporaneidade. A atuação docente nestes ambientes depende das orientações 
médicas, do tipo de doença e do estado de saúde do aluno. Os professores que realizam o atendimento pedagógico ao escolar em tratamento de saúde são do Município ou do Estado das cidades brasileiras que ofertam esse atendimento, que é um direito que deve ser estendido a todas as crianças e adolescentes. O discente que obteve alta hospitalar e liberação médica para continuar a estudar, mas que não pode frequentar o ambiente físico da escola, continua tendo direito ao APETS nos seus diferentes contextos de ensino.

O APETS contribui na recuperação da saúde e na continuidade do processo de escolarização, de inclusão e democratização do ensino. Dependendo do tratamento médico e do tipo de doença, o aluno pode passar anos recebendo escolarização em diferentes ambientes. Neste caso, o processo de ensino e de aprendizagem pode ser mediado pelas tecnologias; a utilização dos meios tecnológicos funciona como um recurso a favor da aprendizagem e pode oferecer possibilidades diferenciadas para facilitar o ensino diante da situação de saúde do aluno.

$\mathrm{Na}$ atualidade, diante da legislação da educação no Brasil, o atendimento ao escolar em tratamento de saúde ainda não tem a garantia efetiva dos órgãos federais e muito menos dos ligados oficialmente a uma secretaria do Ministério da Educação. Esse atendimento pedagógico ao escolar em tratamento de saúde acontece somente em alguns estados e municípios do Brasil. Embora a Constituição Federal e a Lei de Diretrizes e Bases da Educação Nacional (LDBEN), Lei no 9.394 (BRASIL, 1996), promulgue que a educação é um direito de todos, existem professores e pesquisadores engajados nesta causa e que lutam pela efetivação de uma política educacional que seja voltada ao APETS, que esclareça os pais e os docentes, que garanta e direcione essa modalidade de educação aos alunos afastados da escola por problemas de saúde.

\section{O processo da formação continuada online destinada aos professores que atuam com escolares em tratamento de saúde}

Este artigo apresenta uma pesquisa aprovada pelo conselho Nacional de Desenvolvimento Científico e Tecnológico (CNPq) denominada "Eu- reka - Ambiente Virtual favorecendo a formação continuada online dos professores que atuam com escolares em tratamento de saúde". A pesquisa contou com a participação dos docentes do mestrado e doutorado do Programa de Pós-Graduação em Educação (PPGE) da Pontifícia Universidade Católica do Paraná (PUCPR), especificamente os docentes do grupo de pesquisa Paradigmas Educacionais e Formação de Professores (PEFOP), juntamente com os mestrandos, doutorandos e alunos do Programa Institucional de Bolsas de Iniciação Científica e Tecnológica (PIBIC) da graduação em Pedagogia.

Essa pesquisa teve como foco a formação continuada para contribuir com o desenvolvimento profissional dos professores que atuam no atendimento pedagógico ao escolar em tratamento de saúde e o levantamento das repercussões dessa formação pedagógica. Para tanto, aliada às discussões da temática pelo grupo PEFOP, foi proposto o curso de extensão denominado "Formação continuada online para professores que atuam com escolares em tratamento de saúde", que começou a ser criado em março de 2012. Neste mesmo mês iniciaram as reuniões para criar, organizar e desenvolver o curso com os docentes e discentes do Programa de Mestrado e Doutorado em Educação da PUCPR, juntamente com as professoras das Secretarias Estadual da Educação do Paraná (SEED) e Municipal da Educação de Curitiba (SME) que atuam no APETS. Foram realizadas 18 reuniões para criar e desenvolver o curso no Ambiente Virtual de Aprendizagem (AVA) Eureka.

A execução do projeto de pesquisa aconteceu durante os anos de 2012 a 2014, e no último ano ocorreu a entrega do relatório técnico ao $\mathrm{CNPq}$ com as repercussões da pesquisa desenvolvida. No ano de 2012, os docentes dos grupos de pesquisa mencionados, juntamente com os alunos, começaram a desenvolver um curso de extensão denominado "Formação Continuada online para Professores que atuam com Escolares em Tratamento de Saúde". Esta formação foi realizada no AVA Eureka da PUCPR e ofertada gratuitamente a todos os professores (Pedagogos e Licenciados) que participaram do curso e que atuam no APETS.

O AVA Eureka da PUCPR apresenta relevante contribuição ao desenvolvimento do processo de 
ensino e aprendizagem e de pesquisas. Na atualidade existem mais de 200 mil usuários na plataforma Eureka que estão interagindo diante do processo de ensino e aprendizagem virtual. Este AVA permite em sua plataforma uma rica possibilidade de comunicação e interação, que permite produzir conhecimento perante a cultura cibernética em tempo e espaços diferentes. A possibilidade de aproximar pessoas sem que seja preciso deslocamentos, para compartilhar documentos, propostas, dúvidas e questionamentos, é o que torna esse ambiente um importante recurso na construção coletiva do conhecimento. OAVA Eureka apresenta uma interface agradável, de fácil utilização, com funcionalidades síncronas e assíncronas que permitem a comunicação entre todos os participantes, bem como o acesso aos conteúdos disponibilizados pelos professores.

Nesse ambiente virtual de aprendizagem o curso de extensão destinado aos professores que atuam no APETS foi criado e desenvolvido com a intenção de proporcionar uma formação continuada pedagógica que pudesse ampliar e ressignificar o desenvolvimento profissional docente em um espaço de construção de conhecimento e de aprendizagem colaborativa. Este ambiente virtual de aprendizagem é um recurso a favor do ensino, pois os docentes podem utilizá-lo como um meio que permite que a aprendizagem ocorra em diferentes níveis e contextos de ensino. Diante do contexto do APETS, evidencia-se a necessidade de criar novas possibilidades de ensino e aprendizagem em que os docentes estejam preparados para utilizar os ambientes virtuais no processo de escolarização e assim garantir o direito à educação e saúde em espaços diferenciados com o uso de tecnologias que podem contribuir para a continuidade dos estudos.

O curso de extensão denominado "Formação continuada online para professores que atuam com escolares em tratamento de saúde" ficou pronto em junho de 2012, iniciou em agosto e finalizou em novembro do mesmo ano. A formação continuada apresentou 12 unidades por meio do curso online, assim distribuídas:

a) Na unidade 1 foram oferecidas Informações Básicas que tinham o objetivo de informar sobre as etapas do curso, do AVA Eureka e do seu tutorial, da agenda, do andamento das tarefas e demais informações pertinen- tes ao curso. Nesta unidade o aluno teve seis atividades de leitura para poder conhecer bem o curso, seu andamento e o ambiente virtual de aprendizagem.

b) $\mathrm{Na}$ unidade 2 foi proposto um Fórum de Ambientação e Integração, que possibilitou ao participante do curso conhecer o AVA Eureka, todas as suas possibilidades de comunicação e interação, seus recursos que possibilitam a construção de conhecimento, a aprendizagem colaborativa neste ambiente virtual. Nesta unidade o participante teve a oportunidade de conhecer o fórum do AVA, como comunicar-se pelo correio, postar links e trabalhos, criar pastas, compartilhar o conhecimento construído e ter acesso ao relatório de notas. Esta unidade apresentou sete atividades que possibilitaram explorar, conhecer e interagir no AVA Eureka.

c) A unidade 3 envolveu a temática sobre o Atendimento Pedagógico Educacional do escolar em tratamento de saúde, apresentou um panorama sobre o APETS e o conceito dessa modalidade de educação não formal. Esta unidade apresentou quatro atividades.

d) A unidade 4 destinou-se a discutir as $\mathrm{Po}$ líticas Públicas Educacionais voltadas ao escolar em tratamento de saúde, na qual as professoras responsáveis pela disciplina realizaram uma reflexão sobre as Políticas Públicas Educacionais voltadas ao escolar em tratamento de saúde. Esta unidade apresentou duas atividades e um fórum foi realizado para discutir sobre as políticas educacionais deste contexto.

e) A unidade 5 teve como foco a Mudança de Paradigma na Educação e na Saúde, na qual se apresentou uma reflexão sobre abordagens conservadoras e inovadoras no trabalho pedagógico que acontece com os escolares em tratamento de saúde. Esta unidade apresentou uma atividade que solicitava a leitura de um texto e a visualização de um vídeo sobre os paradigmas educacionais para a elaboração de um relato sobre a abordagem inovadora no contexto do APETS. 
f) A unidade 6 foi destinada a Educação $e$ Saúde: cuidados básicos do professor no atendimento pedagógico ao escolar em tratamento de saúde. Apresentou duas atividades que solicitavam aos participantes a leitura de um texto, a visualização de alguns vídeos e a participação em um fórum para discutir e refletir sobre os cuidados que o professor do APETS precisa ter para realizar seu atendimento pedagógico. No fórum realizado, o professor responsável pela unidade 6 levou os participantes a discutirem e a relatarem no fórum quais cuidados eles tomavam no atendimento pedagógico, como a lavagem simples das mãos, desinfecção dos materiais utilizados em aula, entre outros.

g) A unidade 7 abordou a proposição do Serviço de Atendimento à Rede de Escolarização Hospitalar (Sareh), da Secretaria da Educação o Estado do Paraná (SEED), na qual as professoras responsáveis pela unidade contextualizaram o atendimento pedagógico que acontece no Paraná destinado aos alunos das escolas públicas do Estado e sua legislação; esta unidade apresentou uma atividade de leitura.

h) A unidade 8 tratou da Escolarização Hospitalar e Atendimento Pedagógico Domiciliar, da Secretaria Municipal da Educação (SME) de Curitiba. As professoras responsáveis pela unidade contextualizaram o atendimento pedagógico que acontece aos alunos das escolas municipais que estão em contexto hospitalar e domiciliar em Curitiba e a sua legislação; esta unidade apresentou uma atividade de leitura, a visualização de vídeos e a produção de um relato.

i) A atividade 9 foi destinada à Contação de História, na qual foram propostas duas atividades que exploravam o mundo da leitura no APETS. A professora responsável pela unidade possibilitou ao participante explorar a sua criatividade na criação de um relato de experiência contando sua história no APTES.

j) A unidade 10 foi destinada às Múltiplas Linguagens, que foram abordadas por duas professoras. Tinha o objetivo de dar subsídios teóricos e práticos para a apropriação das múltiplas linguagens para serem utilizadas no contex to do APETS. Na atividade as professoras realizaram um fórum para discutir as múltiplas linguagens utilizadas com escolares em tratamento de saúde.

k) A unidade 11 do curso foi denominada Portfólio Digital e o grupo PEFOP considerou o ponto alto da formação online. O participante do curso foi orientado a criar um portfólio digital no AVA Eureka, que teve o objetivo de armazenar as atividades realizadas na formação continuada que foram mais significativas para a aprendizagem do participante e também apresentar uma atividade pedagógica realizada com o escolar em tratamento de saúde. O participante teve autonomia para criar o seu portfólio digital, pois tinha liberdade para usar sua criatividade, sem que uma regra fosse imposta para sua criação. Para apresentar a atividade pedagógica no APETS, o participante pode utilizar inúmeros recursos como fotos, links de vídeos, entrevistas, metodologias diversificadas, relatos de visitas, depoimentos, práticas pedagógicas realizadas, entre outras atividades. O portfólio fez parte da avaliação do curso, juntamente com as atividades realizadas durante as unidades.

1) A unidade 12 foi destinada ao Seminário Final, que acolheu um fórum para que os participantes pudessem discutir os pontos positivos e negativos do curso, as contribuições, as falhas do processo formativo, sugestões para melhoria e demais assuntos pertinentes à formação do professor que atua no APETS.

A equipe de professores que atuaram no curso de extensão online foi composta por três professoras doutoras do Programa de Pós-Graduação em Educação da PUCPR - Mestrado e Doutorado, com dois alunos de mestrado e um de doutorado, juntamente com duas professoras da Secretaria Estadual da Educação do Paraná, duas professoras da Secretaria Municipal da Educação de Curitiba e uma professora voluntária com experiência em contação de histórias. 
As unidades que compunham o curso de extensão tiveram a preocupação de teorizar e contextualizar a prática do professor no APETS. O curso de extensão online teve uma carga horária de 60 horas. Depois que as unidades do curso ficaram prontas, começou a organização de todas as unidades desenvolvidas, com seus respectivos materiais de leitura e com os demais recursos de mídia utilizados no AVA. Todos os professores do curso de extensão gravaram um vídeo de boas-vindas e explicaram aos participantes como aconteceria o desenvolvimento da unidade e das atividades propostas.

Os pesquisadores combinaram a forma de divulgação do curso; para tanto, elegeram mídias, e-mail e a rede social facebook. Após o convite online, os organizadores da formação continuada receberam 2.458 e-mails de professores de todo o Brasil, interessados em participar do curso. Os docentes envolvidos receberam um questionário diagnóstico para selecionar quem iria participar da pesquisa e da formação e somente 295 atenderam ao critério de atuar no APETS. Não foram objeto de investigação os demais interessados, que foram acolhidos em outras versões do curso.

O levantamento sobre o universo investigado permitiu identificar que os participantes da pesquisa são pedagogos e professores de diversas licenciaturas que atuam no APETS de diferentes estados do Brasil. Os participantes envolvidos apresentam como dados: a) Idade: $60 \%$ dos participantes apresentam idade entre 41 e 50 anos; b) Vínculo Empregatício: $70 \%$ dos participantes apresentam vínculo empregatício nas Secretarias da Educação dos Estados; c) Localização: 65\% dos participantes são do Estado do Paraná. Participantes de outros Estados advêm da Bahia, de Minas Gerais, do Pará, do Rio de Janeiro, do Rio Grande do Sul e de São Paulo; d) Local de atuação Profissional: $65 \%$ dos participaram do curso atuam realizando atendimento pedagógico no hospital; e) Tempo de Atuação Profissional: 55\% dos participantes têm de 7 a 10 anos que realizam o atendimento pedagógico ao escolar em tratamento de saúde; f) Formação: $80 \%$ dos participantes apresentam especialização.

O processo de avaliação foi definido pelos professores e seguiu a seguinte orientação: o participante do curso irá receber a certificação se realizar $70 \%$ das atividades desenvolvidas nas unidades e deve também postar o portfólio digital no AVA Eureka. O curso apresentou oito unidades que realizaram avaliação de uma atividade proposta. Cada docente responsável pela unidade enviou um relatório das avaliações já com uma nota que foi utilizada para realizar uma avaliação geral do participante. O curso iniciou no dia 30 de agosto, com 5 salas virtuais no AVA Eureka. A Tabela 1 apresenta uma comparação entre as cinco salas virtuais do curso de extensão em relação aos itens: quantidade de participantes; sexo: masculino e feminino; acesso e não acesso ao AVA Eureka; quantidade de portfólio digital não postado; aprovação e reprovação.

Tabela 1 - Comparação entre as salas virtuais do curso de extensão

\begin{tabular}{lccccc}
\hline & Sala 1 & Sala 2 & Sala 3 & Sala 4 & Sala 5 \\
\hline Quantidade de Participantes & 57 & 63 & 63 & 55 & 57 \\
Sexo Masculino & 3 & 6 & 4 & 2 & 1 \\
Sexo Feminino & 54 & 57 & 59 & 53 & 56 \\
Acessaram o AVA & 52 & 60 & 63 & 54 & 57 \\
Não acessaram o AVA & 5 & 3 & 0 & 1 & 0 \\
Não postaram o Portfólio Digital & 23 & 22 & 24 & 16 & 20 \\
Quantidade de Participantes Aprovado & 34 & 41 & 39 & 38 & 37 \\
Quantidade de Participantes Reprovado & 23 & 22 & 24 & 17 & 20 \\
\hline
\end{tabular}

Fonte: Elaborado pelos autores deste artigo. 
Em relação à comparação entre as cinco salas virtuais do curso de extensão, podemos verificar que o maior número de participantes se encontra nas salas 2 e 3 . O maior número de participantes do sexo masculino ocorreu na sala 2 , com 6 participantes. O total de participantes do sexo masculino no curso foi de 16 , e o total de participantes do sexo feminino foi de 279 . O total de participantes que não acessaram o AVA Eureka foi de 9 . A sala 3 apresentou o maior número de portfólios não postados, e a sala 2 obteve o maior número de participantes aprovados, um total de 41. O total de participantes aprovados no curso de extensão foi de 189. A sala 3 obteve o maior número de participantes reprovados, que foi 24 participantes. $O$ total de participantes reprovados no curso de extensão online foi de 106.

Os elementos descritos na criação e no desenvolvimento do curso de extensão online foram compreendidos como fontes para o exercício da investigação que contribui para a análise dos dados, bem como para a construção de conhecimentos pertinentes à formação docente e seu desenvolvimento profissional.

\section{Encaminhamento Metodológico}

A investigação tinha como objetivo analisar a formação continuada online ofertada aos professores que atuam no APETS e as repercussões dessa formação para o desenvolvimento profissional docente. $\mathrm{Na}$ investigação optamos pela pesquisa qualitativa na modalidade online, do tipo estudo de caso, de natureza interpretativa. Com este propósito foi possível analisar as implicações e contribuições dos docentes que participaram do curso com a finalidade de indicar pontos norteadores para uma futura formação pedagógica dos professores, especialmente com os que atuam com escolar em tratamento de saúde. As discussões foram focadas nas relações entre educação e saúde, com ênfase no processo de formação continuada do professor que optou pela docência na educação não formal.

A pesquisa qualitativa realizada por meio da modalidade online se caracteriza quando o pesquisador faz o uso da internet e do computador para realizar todo processo investigati- vo planejado. Segundo Flick (2013, p. 164), a pesquisa qualitativa na modalidade online "[...] usa a internet como um instrumento para a realização de uma pesquisa [...]”. A internet é vista como um instrumento de investigação que permite ao pesquisador uma ampla e vasta gama de possibilidades para realizar a pesquisa qualitativa com recursos disponibilizados online. A pesquisa apresentou condições favoráveis para que as investigações fossem executadas online, e como optamos por um estudo de caso, cabe o esclarecimento de Bogdan e Biklen (1994, p. 89), no qual apontam que "[...] o estudo de caso consiste na observação detalhada de um contexto, ou indivíduo, de uma única fonte de documentos ou de um acontecimento específico".

Os envolvidos na pesquisa tiveram a garantia do anonimato por meio do Termo de Consentimento Livre e Esclarecido enviado e respondido online por meio do AVA Eureka. Todos os participantes do curso online aceitaram participar da investigação. A pesquisa desenvolvida foi aprovada pelo Comitê de Ética em Pesquisa da PUCPR sob o parecer $n^{\circ}$ 852.829 .

O instrumento utilizado para a coleta de dados durante a realização desta pesquisa foi o questionário com perguntas abertas e fechadas. Este instrumento de coleta de dados foi confeccionado coletivamente pelos professores do curso de extensão online. Dois questionários foram construídos: um questionário processual e outro formativo. Esses dois instrumentos tinham o objetivo de coletar informações sobre o curso ofertado aos professores que atuam no APETS. O questionário processual apresentou 4 perguntas abertas e 3 fechadas, referentes ao conteúdo das disciplinas ministradas, aos conhecimentos adquiridos pelo curso e sobre a atuação do professor no APETS. O questionário formativo apresentou 7 perguntas fechadas e 10 abertas, referentes às repercussões da formação para o desenvolvimento profissional docente.

Os dois questionários confeccionados foram enviados aos participantes do curso por e-mail, pela plataforma de comunicação do AVA Eureka. Em relação à quantidade de questionário respondidos, a Tabela 2 apresenta esse número por sala. 
Tabela 2 - Quantidade de questionários respondidos por sala

\begin{tabular}{lccccc}
\hline & Sala 1 & Sala 2 & Sala 3 & Sala 4 & Sala 5 \\
\hline Número de participantes & 57 & 63 & 63 & 55 & 57 \\
Questionário Processual & 23 & 27 & 25 & 22 & 24 \\
Questionário Formativo & 22 & 28 & 24 & 13 & 22 \\
\hline
\end{tabular}

Fonte: Elaborado pelos autores deste artigo.

Como podemos observar na Tabela 2, dos 295 participantes de todas as salas, 121 questionários (questionário processual) foram respondidos. No questionário formativo, dos 295 participantes de todas as salas, 109 questionários foram respondidos. Os questionários recebidos foram codificados para realizar a análise de conteúdo e para manter uma postura ética da pesquisa da seguinte forma: a sigla QAP significa questionário da avaliação processual; a expressão numérica 001 corresponde ao professor que participou do curso, sua identificação; a sigla $\mathrm{S} 1$ significa a sala do curso que o participante pertence. Todas essas informações unidas formaram um código QAP001S1, que apresenta o seguinte significado: questionário da avaliação processual do professor 001 da sala 1 do curso de extensão online. Para cada participante do curso foi criado um código com essas informações e esse mesmo processo aconteceu para o questionário formativo. Depois que os questionários estavam todos com códigos, os mesmos foram adicionados ao software de análise de dados qualitativos Atlas Ti para iniciar o processo de análise.

A análise de dados é uma fase importante na pesquisa qualitativa; objetiva organizar, interpretar e analisar os dados coletados. É o processo pelo qual o pesquisador procura dar ordem, estrutura e significado aos dados coletados. A análise dos dados realizada na pesquisa deste artigo foi a análise de conteúdo, muito utilizada para analisar materiais em forma de texto de qualquer origem. Enquanto método, a análise de conteúdo é um conjunto de técnicas de análise das comunicações que utiliza procedimentos sistemáticos e objetivos de descrição do conteúdo das mensagens (BARDIN, 2011). Para Flick (2013, p. 134), “[...] a análise de conteúdo tem por objetivo classificar o conteúdo dos textos alocando as declarações, sentenças ou palavras a um sistema de categorias". A análise de conteúdo foi realizada nos dados coletados dos questionários (processual e formativo) com o auxílio do software Atlas Ti, e as etapas da análise de conteúdo se deu nos dois questionários da seguinte forma:

a) Etapa 1 - Coleta de Dados: Os dados colocados no software advêm de dois questionários que foram enviados por e-mail aos participantes da pesquisa. Os questionários foram recebidos no e-mail dos professores do curso. Os questionários foram criados no Microsoft Word e por meio destes instrumentos foi realizada a coleta de dados.

b) Etapa 2 - Preparação dos Dados: Foram utilizados os dois questionários na análise de conteúdo (processual, 121 questionários, e formativo, 109 questionários). Esses instrumentos de coleta de dados foram codificados com um código para cada questionário respondido, conforme já mencionado acima.

c) Etapa 3 - Utilização do Software Atlas Ti: Os questionários codificados que foram respondidos e que estavam salvos no formato doc, docx e pdf foram inseridos no software Atlas Ti.

Etapa 3.1 - Codificação: A etapa da codificação foi realizada com a criação dos códigos para realizar a categorização. Os códigos representam um sistema de símbolos que permite a representação de uma informação. Os códigos foram criados a partir do momento que inicia a codificação, com a leitura das respostas dos participantes. Para cada resposta foi criado um código, e as respostas iguais ou semelhantes recebiam um código já criado anteriormente. Os 
códigos foram agrupados por semelhança ou incidência e deram origem às categorias de análise.

Etapa 3.2 - Categorização: A categorização é a união ou o conjunto dos códigos por incidência ou semelhança que permite ao pesquisador agrupar os dados para consolidar um significado. Depois que todas as perguntas dos dois questionários foram codificadas, foi visualizado no Atlas Ti os códigos que tiveram maior incidência de respostas. Todas as respostas (quotations) de um código com maior incidência foram analisadas pelo pesquisador. A análise das respostas foi realizada da seguinte maneira: 1) Leitura cuidadosa das respostas dos participantes; 2) Reflexão do pesquisador sobre cada resposta; 3) Identificação e criação de grupos com pontos de convergência entre as respostas para consolidar um significado.

\section{Criação das categorias a partir das respostas dos participantes}

Conhecidas as respostas dos participantes, estas passaram a constituir-se como indicadores para a criação das categorias. Para isso, os pesquisadores foram em busca do significado e do sentido das respostas dos participantes, e na medida em que estavam interessados também em saber a intensidade do aparecimento dos significados lógicos semânticos, decidiram quantificar as frequências absolutas e relativas das respostas. Para a análise dos dois questionários, foram elaborados quadros que explicitam as categorias criadas e alguns de seus indicadores (respostas). No questionário de avaliação processual foram analisadas todas as questões formuladas (abertas e fechadas). No questionário formativo foram analisadas cinco perguntas abertas. As respostas dos participantes dos questionários (processual e formativo) ajudaram a responder o objetivo do artigo.

O quadro apresentado a seguir apresenta três respostas que foram utilizadas como exemplos para a criação das categorias e o total de respostas de cada categoria. A soma total de respostas de cada categoria criada corresponde à quantidade de incidência que o código deve. Como exemplo de como a análise foi realizada nas respostas dos questionários, na pergunta 7 do questionário formativo indagamos o seguinte: Quais foram as contribuições da formação continuada online para o seu desenvolvimento profissional? A resposta que apresentou maior incidência para essa pergunta foi que a formação continuada online contribuiu para a aquisição de novos conhecimentos, com 41 incidências. A pergunta realizada tinha o objetivo de levantar quais foram as contribuições da formação continuada para o desenvolvimento profissional. No Quadro 1 apresentamos as categorias que foram criadas a partir da resposta dos participantes.

Quadro 1 - Alguns motivos explicitados pelos participantes para justificar as contribuições da formação continuada online em relação à aquisição de novos conhecimentos

\section{Motivos Explicitados Participantes}

\section{(CATEGORIA) - Relacionados ao APETS}

"Essa formação contribuiu para que eu pudesse adquirir novos conhecimentos em relação ao atendimento pedagógico ao escolar em tratamento de saúde".

"Adquiri muitos conhecimentos neste curso, muitos assuntos são novos, relacionados à prática do professor além dos muros da escola".
Total de respostas: 28

QAF012S2

QAF010S5 


\begin{tabular}{|l|l|}
\hline $\begin{array}{l}\text { "Temas relevantes, novos conhecimentos } \\
\text { relacionados ao atendimento pedagógico ao } \\
\text { escolar em tratamento de saúde". }\end{array}$ & QAF003S4 \\
\hline $\begin{array}{l}\text { (CATEGORIA) - Relacionados ao } \\
\text { desenvolvimento profissional }\end{array}$ & Total de respostas: 13 \\
\hline $\begin{array}{l}\text { "Os novos conhecimentos adquiridos no } \\
\text { curso me ajudaram muito profissionalmente, } \\
\text { me esclareceram sobre dúvidas que eu tinha; } \\
\text { por exemplo, os cuidados que eu devo ter } \\
\text { no atendimento pedagógico ao escolar em } \\
\text { tratamento de saúde. }\end{array}$ & QAF022S1 \\
\hline $\begin{array}{l}\text { "Foram muitos os temas trabalhados no curso; } \\
\text { adquiri conhecimentos que serão muito úteis } \\
\text { para o meu desenvolvimento profissional. São } \\
\text { poucas as possibilidades de formação continuada } \\
\text { nesta área, valeu muito a pena". }\end{array}$ & QAF021S5 \\
\hline $\begin{array}{l}\text { "O curso possibilitou a aquisição de novos } \\
\text { conhecimentos que foram fundamentais para } \\
\text { me desenvolver profissionalmente, pois a partir } \\
\text { desses conhecimentos me torno um profissional } \\
\text { melhor, mais preparado". }\end{array}$ & QAF027S2 \\
\hline
\end{tabular}

Fonte: Elaborado pelos autores deste artigo.

No Quadro 1, foi possível verificar que 28 participantes mencionaram que a formação continuada online contribuiu na aquisição de novos conhecimentos relacionados ao atendimento pedagógico ao escolar em tratamento de saúde. Concordamos com as respostas dos participantes, pois um curso de extensão ou especialização precisa contribuir de alguma maneira para a aquisição de novos conhecimentos. $\mathrm{O}$ fato dos participantes terem sinalizado que o curso contribuiu para a aquisição de novos conhecimentos relacionados ao APETS mostra um avanço, uma significativa contribuição aos professores que atuam e se desenvolvem profissionalmente a partir dos novos conhecimentos adquiridos na formação, já que a temática é pouco pesquisada e são poucas também as oportunidades de formação continuada.

Diante da análise de conteúdo realizada nos dois questionários, buscamos responder o objetivo da pesquisa e descrever as contribuições da formação continuada online para o desenvolvimento profissional do professor que atua no APETS.

\section{Análise e Considerações Finais}

A pesquisa permitiu investigar a formação continuada online para o desenvolvimento profissional dos professores que atuam no atendimento pedagógico ao escolar em tratamento de saúde. Para tanto, o problema que norteou o processo investigativo foi: Como a formação continuada online pode contribuir para o desenvolvimento profissional dos professores que atuam no atendimento pedagógico ao escolar em tratamento de saúde e quais as repercussões dessa formação pedagógica? Para responder ao problema proposto tínhamos como objetivo geral analisar o processo de formação continuada online ofertada aos professores que 
atuam no APETS e as repercussões dessa formação para o desenvolvimento profissional docente, a fim de indicar pontos norteadores para uma futura formação pedagógica aos docentes que atuam com escolar em tratamento de saúde.

Para alcançar tal objetivo, organizou-se um processo de formação continuada online, especificamente, um curso de extensão que foi destinado aos professores que atuam no APETS, curso este que advém de uma pesquisa aprovada pelo CNPq. O curso de extensão online criado foi denominado de "Formação Continuada online para Professores que atuam com Escolares em Tratamento de Saúde". A formação proposta visou o desenvolvimento profissional do professor que atua no APETS, compreendendo-o como um progresso permanente para a formação, relacionado a um processo de mudança do docente e de sua prática pedagógica; de melhoria das competências profissionais; da conscientização de seu papel como docente que atua além dos muros da escola, em diferentes contextos de ensino; na aquisição de novos conhecimentos que envolvem a dimensão pessoal e profissional.

Em aderência a essa proposta, elegeu-se a abordagem qualitativa do tipo estudo de caso, entendendo que esse tipo de pesquisa permite o envolvimento ativo do pesquisador na busca por respostas, em investigar como acontecem as relações ou os fenômenos formativos e educacionais, respeitando a subjetividade dos participantes, com a intenção de promover uma formação continuada com o intuito de contribuir com o desenvolvimento profissional. A pesquisa realizada permitiu o envolvimento com o objeto de investigação e, ao mesmo tempo, refletir sobre ele, analisá-lo, sem perder a noção do todo.

A presente pesquisa não pretende traçar metas a respeito do processo de formação continuada dos professores que atuam no APETS, mas sim contribuir com pontos norteadores que ajudem na criação e no desenvolvimento de processos formativos que permitam a aquisição e a ampliação de conhecimentos.

Com isso, a convergência dos resultados de todo o processo da pesquisa, incluindo a criação e o desenvolvimento do curso de extensão online e a análise de conteúdo realizada nos questionários, permitiu realizar categorias de análise como elementos definidores que permitiram delinear alguns aspectos possíveis de serem considerados na formação continuada online dos professores que atuam no APETS, com vistas a contribuir para o desenvolvimento profissional desse professor que atua além do contexto formal de ensino. Analisando o processo de formação continuada online ofertada aos professores que atuam no APETS e as repercussões dessa formação para o desenvolvimento profissional, enfatizamos como a formação continuada online contribui para o desenvolvimento profissional docente:

- Aformação continuada torna-se mais significativa para o desenvolvimento profissional quando é criada e organizada numa perspectiva coletiva, no diálogo entre os pares (formadores). A construção da formação continuada na coletividade incentiva a apropriação de conhecimentos entre todos os envolvidos no processo, contribui para o desenvolvimento profissional docente em particular e no coletivo.

- A formação continuada precisa considerar o perfil dos participantes para poder estabelecer as avaliações e o tempo para a realização das atividades. Identificar o perfil dos participantes contribui para que os formadores possam estabelecer melhor o processo de ensino e aprendizagem, levando em conta as relações entre docência e tempo.

- Os conteúdos trabalhados na formação continuada precisam contemplar a relação entre educação e saúde e os contextos de ensino do APETS.

- Os materiais utilizados no processo formativo precisam estar em vários formatos (vídeos, links, e-books, artigos etc.).

- Os professores que fazem parte do processo formativo precisam contextualizar a teoria e a prática nos diferentes contextos de ensino, sabendo que o meio ambiente influencia o processo de aprendizagem. Daí a importância dos diferentes contextos de ensino do APETS enquanto ambiente que propicia a formação contínua dos professores, contribuindo para seu desenvolvimento profissional, e enquanto 
espaço democrático, comprometido com a transformação das relações sociais.

- A formação continuada precisa partir das necessidades dos professores para contribuir com o desenvolvimento profissional. A formação continuada é um caminho percorrido por aqueles que sentem necessidade de desenvolvimento profissional, que buscam ter consciência das dificuldades reais enfrentadas na profissão, na possibilidade de ressignificar e construir ações para os reais problemas educacionais. A formação precisa estar conectada às realidades e aos desejos e valores da docência para que possa realmente contribuir para o desenvolvimento profissional.

O processo de formação continuada desenvolvido foi relevante, levando em conta as características da formação como curso de extensão. O processo de criação e de desenvolvimento do curso foi concebido na perspectiva do trabalho coletivo entre os pesquisadores da universidade e os professores que atuam no APETS que foram formadores.

As repercussões da formação continuada online para o desenvolvimento profissional docente foram positivas diante do formato e da organização do curso. Com base nas respostas dos participantes, nas incidências dos códigos e nas categorias de análise, pudemos identificar que as repercussões da formação para o desenvolvimento profissional estão relacionadas aos pontos indicados a seguir.

1. Contribuições da Formação Continuada online para o Desenvolvimento Profissional Docente:

- Possibilitou a aquisição de novos conhecimentos sobre o APETS. O curso, mesmo sendo direcionado aos professores que já atuam no atendimento pedagógico ao escolar em tratamento de saúde, proporcionou aos docentes adquirir novos conhecimentos que estão relacionados ao APETS. Isso podemos verificar na categoria de análise das contribuições da formação continuada online para o desenvolvimento profissional em relação à aquisição de novos conhecimentos.

- Contribuiu para a reflexão sobre a prática. Para que o professor possa se desenvolver profissionalmente, é importante refletir sobre a prática docente, não só na perspectiva de pensar sobre o que está fazendo, mais sim de tornar isso uma ação concreta, ressignificando e aprendendo constantemente para seu desenvolvimento pessoal e profissional.

- Possibilitou ampliar conhecimentos. A possibilidade de ampliar conhecimentos é um fator relevante para o desenvolvimento profissional. A ampliação de conhecimentos permite a aprendizagem permanente, que irá certamente influenciar no desenvolvimento profissional docente.

- Possibilitou colocar os conhecimentos em prática. A aplicabilidade de conhecimentos a partir da formação continuada na realidade do professor mostra que o curso de extensão contribuiu não só para o desenvolvimento profissional docente, mas também para a prática pedagógica do docente que atua em diferentes contextos de ensino. A aprendizagem adquirida na formação continuada permitiu aplicar os conhecimentos no contexto do APETS.

- Permitiu trocar experiências entre os participantes. Durante a análise dos questionários foi possível identificar que a troca de experiências entre os participantes enriquece o processo de formação e o desenvolvimento profissional. Possibilita também ampliar conhecimentos e práticas, já que a literatura neste contexto é limitada.

- Contribuiu como um curso a distância, na modalidade online. O curso de extensão online atendeu as necessidades dos participantes, flexibilizou a utilização de diferentes recursos de interação do AVA e de materiais, bem como permitiu reunir pessoas de diferentes estados que atuam no mesmo segmento educacional e, principalmente, possibilitou que a formação acontecesse a distância.

As contribuições da formação continuada online estão relacionadas à capacidade e a condição de aprendizagem do participante, da possibilidade de refletir e colocar em prática os conhecimentos adquiridos no curso que aconteceu à distância, na 
modalidade de educação online, o que possibilitou a troca de experiências entre os participantes de diferentes estados brasileiros, contribuindo de maneira diversa ao desenvolvimento profissional docente.

2. Implicações da Formação Continuada online:

- A maior dificuldade no decorrer do curso está relacionada à falta de tempo. Foi possível identificar que os participantes em suas contribuições apontaram que as dificuldades no decorrer do curso estão relacionadas à falta de tempo para realizar as atividades. A falta de tempo advém de excesso de trabalho e da quantidade de atividades profissionais e pessoais.

- Acrescentaria mais tempo para realizar as atividades do curso. $\mathrm{Na}$ análise dos dados foi possível identificar que os participantes, em suas contribuições, apontaram que acrescentariam mais tempo para melhorar o curso online. Tal necessidade advém da relação do professor com o trabalho, da sua sobrecarga de atividades, da complexificação da profissão. A organização do tempo é fundamental para o processo de aprendizagem na educação online. É necessário que o docente organize sua vida profissional para poder ter tempo para estudar, aprender em cursos a distância.

- Retiraria o chat. Nas contribuições dos participantes foi possível verificar que muitos dos professores não gostaram da metodologia utilizada no chat. Alegaram que esse recurso de comunicação e interação do AVA não contribuiu para a aprendizagem, reclamaram do horário que o chat acontecia, no domingo às nove horas, e indicam que gerou dificuldade de se organizarem na atividade.

- Retiraria o prazo de uma semana para realizar as atividades. Foi possível identificar que os participantes ampliariam o prazo de uma semana para realizar as atividades do curso online para torná-lo melhor. A questão da dificuldade com o tempo ficou evidente nas contribuições dos professores. Pudemos identificar que as implicações da formação continuada online estão relacionadas à falta de tempo do participante, tanto em relação à questão da sobrecarga de trabalho, quanto da vida pessoal. As implicações que aconteceram na formação permitiram olhar com mais atenção a questão do perfil do participante do curso.

\section{Pontos norteadores para a Formação Pedagógica dos profissionais que atuam no APETS}

Diante das contribuições e implicações da formação continuada online foi possível identificar pontos norteadores para futuras formações dos professores que atuam no atendimento pedagógico ao escolar em tratamento de saúde. Com isso, apresentamos os principais pontos que foram relevantes para a formação:

- A unidade de Mudança de Paradigmas na Educação e na Saúde e seus reflexos no atendimento pedagógico ao escolar em tratamento de saúde foi uma disciplina que contribuiu para o desenvolvimento profissional do participante, pois tinha o objetivo de gerar uma reflexão sobre as abordagens conservadoras e inovadoras do trabalho pedagógico com o escolar em tratamento de saúde. Foi possível identificar nas contribuições dos participantes que a disciplina possibilitou uma reflexão sobre a necessidade de mudança de Paradigmas na Educação e na Saúde, sendo um conteúdo importante para o APETS, pois permite a mudança da prática pedagógica.

- A leitura crítica e reflexiva dos materiais disponíveis do curso contribui para a formação quando está associada à interação dos participantes por meio da troca de experiências. Essa ação conjunta facilita o processo de aprendizagem.

- A aplicabilidade dos conhecimentos adquiridos durante o curso necessita estar relacionada aos diferentes contextos de ensino, e a relação entre teoria e prática pedagógica precisa destacar esses diferentes contextos de ensino.

- $\quad$ A unidade de Contação de História foi uma disciplina que contribuiu para o desenvolvimento profissional do participante, pois 
proporcionou ao participante transformar um relato de vida em um conto de fadas. Nas contribuições dos professores ficou evidente a satisfação em realizar a atividade, muitos comentaram que utilizaram a contação de história para ensinar nos diferentes níveis e contextos de ensino.

- O Portfólio Digital foi uma atividade que muitos professores desconheciam a utilidade no processo de ensino e aprendizagem. Depois que os participantes entenderam o que é um portfólio e qual é a sua função no processo de ensino, muitos docentes construíram seus portfólios digitais com as suas aprendizagens mais significativas para a sua ação docente e produziram o portfólio utilizando recursos como o power point, imagens, fotos, vídeos, relatos etc. Nesta atividade pudemos conhecer (por fotos e vídeos) os diferentes contextos de ensino em que os professores fazem o APETS.

- A continuidade do processo formativo foi uma questão que estava presente nas participações dos professores. Existe uma carência tanto de literatura quanto de processos formativos para os professores que atuam no APETS, principalmente para os outros contextos de atuação, como o atendimento pedagógico domiciliar.

- Os pontos norteadores desta formação continuada online são fundamentais para a construção e o desenvolvimento de futuros processos formativos para o APETS, pois eles servem de subsídios para a formação do professor. São pontos de referência que permitem colaborar com a formação, com o desenvolvimento profissional, pois são elementos que foram identificados por meio da pesquisa e podem ajudar no desenvolvimento de cursos para a formação de professores que atuam no APETS.

A formação continuada não se apresenta por si só como uma solução para os problemas da educação, mas há o entendimento de que ela permite o aprimoramento e o desenvolvimento profissional, pois possibilita ao professor buscar um paradigma inovador que permita gerar alicerces relevantes no processo de ensino e, assim, contribuir para a ação docente significativa, crítica, reflexiva e transformadora. Ainda existe a necessidade de continuar a oferecer formação continuada para os professores que atuam no APETS, pois a construção de ações coletivas de pesquisadores e professores pode fazer diferença no aprimoramento do desenvolvimento profissional desses docentes.

\section{REFERÊNCIAS}

BARDIN, Laurence. Análise de Conteúdo. 7. ed. São Paulo: Edições 70, 2011.

BOGDAN, Robert C; BIKLEN, Sari Knopp. Investigação qualitativa em educação. Porto: Porto, 1994.

BRANDÃO, Carlos Rodrigues. O que é Educação. 49. ed. São Paulo: Brasiliense, 2007.

BRASIL. Presidência da República. Constituição da República Federativa do Brasil. Brasília, DF, 1988. Disponível em: <http://www.planalto.gov.br/ccivilconstituicao/constituicao.htm>. Acesso em: 06 dez. 2014.

. Presidência da República. Lei n ${ }^{\circ} 8.069 / 90$, de 13 de julho de 1990. Estatuto da Criança e o Adolescente. Brasília, DF, 1990. Disponível em: <http://www.planalto.gov.br/ccivil_03/leis/18069.htm>. Acesso em: 27 fev. 2015.

. Presidência da República. Lei no 9.394, de 20 de dezembro de 1996. Lei de Diretrizes e Bases da Educação Nacional. Brasília, DF, 1996. Disponível em: <http://www.planalto.gov.br/ccivil_03/leis/19394.htm>. Acesso em: 16 fev. 2016.

. Ministério da Educação. Conselho Nacional de Educação/Câmara de Educação Básica. Resolução n 2, de 11 de setembro de 2001. Institui as Diretrizes Nacionais para a Educação Especial para a Educação Básica. Brasília, DF, 2001. Disponível em: <http://portal.mec.gov.br/cne/arquivos/pdf/CEB0201.pdf>. Acesso em: 27 dez. 2014.

FERREIRA, Jacques de Lima. Educação e Saúde: cuidados básicos do professor no atendimento pedagógico ao escolar em tratamento de saúde. In: MATOS, Elizete Lúcia Moreira; FERREIRA, Jacques de Lima Ferreira. Formação Pedagógica para o atendimento ao escolar em tratamento de saúde: redes de possibilidades online. 
Petrópolis, RJ: Vozes, 2013. p. 166-178.

FLICK, Uwe. Introdução à metodologia de pesquisa: um guia para iniciantes. Porto Alegre: Penso, 2013.

GOHN, Maria da Glória. Educação não formal e o educador social: atuação no desenvolvimento de projetos sociais. São Paulo: Cortez, 2010.

LIBÂNEO, José Carlos. Pedagogia e pedagogos, para quê? 12. ed. São Paulo: Cortez, 2010.

MIALARET, Gaston. Ciências da educação: aspectos históricos, problemas epistemológicos. São Paulo: WMF Martins Fontes, 2013.

MORIN, Edgar. Os sete saberes necessários à educação do futuro. São Paulo: Cortez, 2000.

Recebido em: 28.03 .2016

Aprovado em: 09.08.2016 